DOI: $10.20472 / E F C .2017 .008 .010$

\author{
FALIK SHEAR \\ NUST Business School, Pakistan
}
HILAL ANWAR BUTT
IBA, Pakistan

IMTIAZ BADSHAH

NUST Business School , Pakistan

\title{
AN ANALYSIS OF THE RELATIONSHIP BETWEEN THE SOVEREIGN CREDIT DEFAULT SWAPS AND THE STOCK MARKET OF PAKISTAN THROUGH HANDLING OUTLIERS
}

\begin{abstract}
:
This study examines the relationship between the Sovereign Credit Default Swap (SCDS) market and Karachi Stock Exchange (KSE). Previous literature in this lieu rarely handles the effect of outliers' presence in data. This study applies Split Sample Skewness Based Boxplot (SSSBB) technique for outlier detection and proposes SSSBB-Winsorization for handling outliers. The results depict a significant role of outliers in the determination of the correlation and causal relationship between these markets. Findings suggest a negative and statistically significant correlation between SCDS and KSE, which is increasing gradually. Moreover, by using Granger causality test, this study finds bidirectional causality between both the markets, which implies informational efficiency of both markets in the prediction of each other.
\end{abstract}

\section{Keywords:}

Granger causality, KSE, $\square$ Outliers, Sovereign CDS, Winsorization 


\section{Introduction}

The fear of default by the borrower is the nightmare of any financial institution. This risk is called credit risk. One of the ways out of this situation is the use of credit derivatives by financial institutions. Among credit derivatives, Credit Default Swap (CDS) is gaining attention all over the world. The core concept of CDS is the insurance of debt payment by third parties to the lender, in case of default. In words of Huang et al. (2014) "A CDS seller provides insurance against the default risk of a reference entity, and the protection buyer makes periodic payments. The payment, expressed as a percentage of the notional value of the contract, is called the CDS spread, which provides a direct measure of credit risk for the underlying reference entity from a very liquid market". There are two types of CDS. One is Corporate CDS, concerned with CDS of firms and the other one is Sovereign CDS (SCDS), which is related to CDS of a country.

SCDS spreads (SCDSs) are often used as proxy to measure the default or credit risk of a country (Eyssell et al. (2013); Huang et al. (2014)) use SCDSs as a measure of country credit risk). An elevation in SCDSs is the reflection of a country's high credit risk, which may lead to default by the country on its debt payments. It is cogent to assume, if a country is getting closer to default, it may have poor economic and financial situation domestically. Poor performance of the economy should be reflected in the country's stock market as it is the barometer of country's economic health (Eyssell et al., 2013). Consequently, it is argued that an elevation in the SCDSs yield depression in stock exchange of the country, which relays the weak economic situation of the country. Accepting the notion that a country's default should be driven by its poor economic conditions, following question needs to be addressed; which market incorporates information regarding increasing credit risk of a country at an earlier stage, SCDS or stock market? If the stock market incorporates credit risk information at first, then the stock market should Granger cause the SCDS market. As the stock market is operating in the country, it should have more information about economic conditions of the country. Hence, it is expected to Granger cause or lead SCDS, in accordance with the efficient market hypothesis (Eyssell et al., 2013). Meanwhile, previous literature on the SCDS market suggests that the presence of international investors helps it to incorporate information prior to the stock exchange. Considering the fore-described situation, SCDS is expected to hold more information, and it should lead the stock market, when sovereign credit risk increases.

The correlation and causal relationship between SCDS markets and stock exchanges within Asia has been explored previously (e.g. Chan et al. (2009) study this relationship for seven countries: Eyssell et al. (2013) for China). However, these relationships have been scarcely discussed with reference to Pakistan in general and Karachi Stock Exchange (KSE) in particular. This study is an effort to fill this gap. 
Our motivation for studying KSE is driven by its tremendous growth recently. It is ranked as third among the top ten best performing stock markets around the world for 2014, which is its third consecutive year in the top ten group. It also secured top positon in Morgan Stanley Capital International (MSCl) Asian frontier markets by outperforming other Asian markets ${ }^{1}$ and generated $31 \%$ returns(in US\$ terms). Considering its high growth potential, $\mathrm{MSCl}$ is including $\mathrm{KSE}$ in its Emerging-Market index in next year, which is expected to attract more foreign investment into the market. KSE also provide diversification opportunity to international investors due to its low correlation with international stock markets (Akbar and Nguyen, 2016).

The increasing trend to hedge the sovereign credit risks of emerging countries has increased the CDS market for these countries (Chan et al., 2009). The Pakistan SCDS market starts from October 2004 and is being covered by the all major SCDS data providers. Contracts from 6 months up to 10 years are available for Pakistan. This market often reacted promptly in response to worsening economic dynamics. For instance, during 2008-09 Pakistan shows a great financial turmoil. In response to which, SCDS spreads increase more than 300\% during July to December 2008. Afterward, with betterment of economic situation in the country, the market reverts back till the end of 2009. Both the KSE and SCDS market for Pakistan show periods of growth and decay during our study period. For example, KSE shows a high decline in 2008-09 and then rise in performance afterward. Similarly, SCDS market show widening of spreads during this period. Thus both market presents a unique opportunity to study the price discovery function during changing market dynamics. To grasp this opportunity, this study extends its analysis by dividing the sample period into pre-crisis, crisis and post-crisis period.

Another lacuna, which is rarely considered by previous researchers, is the presence of outliers and their subsequent effect on the relationship between both the markets. Outliers are the abnormal values in data and they can affect the empirical estimates. According to Box et al. (2013) existence of outliers within time series data can have a significant effect on forecasting and parameter estimations. Hence, this study intends to handle the effect of outliers on the relationship between the SCDS and stock market (i.e. KSE) of Pakistan. Outlier handling is carried out into two steps. At first, the outliers have been detected through Split Sample Skewness Based Boxplot (SSSBB) technique, which is developed by Adil (2012) for skewed data. Afterwards, the detected outliers are Winsorized. We call this procedure as SSSBB-Winsorization. This strategy consumes fewer number of observation than traditional Winsorization methods and has potential application in studies covering financial markets because these markets generally constitute skewed data.

This article attempts to contribute in the following ways. First, it adds to limited literature available on stock and Sovereign CDS market relationship. Although

\footnotetext{
${ }^{1}$ Pakistan Economic Survey 2014-2015
} 
relationship between stock and CDS markets have been the focus of many studies, but firm-level studies outnumber the country-level. Second, it finds out the nature of causal relationships for both of these markets, for a developing country like Pakistan for the first time to the best of our knowledge. Third, it proposes SSSBB-Winsorization for outlier handling. Fourth, it is useful for domestic and international investors, who are planning to place their investments either in the SCDS market of Pakistan or KSE. Finally, it is helpful for hedgers and speculators who want to hedge and speculate on Pakistan's credit risk.

The remainder of the research work is organized as follows. Section 2 elaborates the previous literature on stock and CDS market relationship and presents hypotheses. This section further highlights importance of outlier and their detection. The next section discusses methodology and handling of outliers. In the fourth section results are analyzed and the final section concludes the study.

\section{Literature Review and hypotheses}

\subsection{Relationship between stock and CDS market}

The relationship between CDS and stock market is derived from the Merton (1974) model, which correlates equity and bond prices of the firm. Chan-Lau and Kim (2004) extend Merton's model for sovereign CDS (SCDS) and stock market relationship. Chan et al. (2009) argue that SCDS and stock market might get integrated due to the use of capital structure arbitrage. For example, during periods of high sovereign credit risk, performance of country's stock market will face decline due to poor domestic economic fundamentals or due to demand of high risk premium by domestic and international investors. Furthermore, in such situation buying insurance against such sovereign would become costly. Thus the SCDS spreads would increase. Furthermore, demand for buying insurance against such sovereign would also increase. This would create further downward pressure on equity prices of the country as seller of SCDS hedge their position by shorting bond or equity of the country. Thus stock and SCDS markets are expected to be negatively correlated (Chan et al., 2009).

When sovereign face high credit risk, the cost of borrowing for sovereigns would increase. This will decrease investments and spending of sovereign and it has to increase taxes. As a result, overall consumption and investment will fall in economy, which would decrease firm profits and share prices. Thus overall stock market performance will decrease (Coronado et al., 2012). Hence we expect a negative relationship between KSE and SCDS market for Pakistan.

The relationship between stock and CDS markets gets more attention of researchers after pioneer study by Longstaff et al. (2003); they study the relationship of the stock 
market with CDS and bond markets by using Vector Auto Regressive (VAR) model ${ }^{2}$. They find the leading role of stock and CDS market over the bond market in discovering new information. However, the clear lead-lag relationship between stock and CDS markets cannot be established.

Further literature on the lead-lag relationship between CDS and stock market can be categorized into two strands. The first strand consists of those studies, which declare the stock market as a leader in the incorporation of information. For instance, in one of the pioneer studies regarding CDS and stock market, Bystrom (2005) uses European" iTraxx CDS market for determining the relationship between CDS and stock market. By comparing seven sectorial indices with respective stock indices, Bystrom (2005) finds an inverse relationship between CDS and stock market. Another important finding is that much of the variations in CDS are explained by stock prices. Thus, he concludes that the stock market incorporates information prior to CDS market and it is an indication of the stock markets proficiency. Another study supporting the dominant role of the stock market is conducted by Forte and Pena (2009). They examine 17 North American and European non-financial firms by using Vector Error Correction Model (VECM) for determination of the relationship between stock market, CDS and bond market. They conclude that the stock market leads the other two markets more frequently. Norden and Weber (2009) augment this literature by studying the relationship between triad (i.e. Stock, bond and CDS market). Their findings also support the existence of negative relationship between CDS spreads and stock market returns. Moreover, they find stock market leads CDS and bonds markets, which is attributed towards more sensitivity and liquidity of the stock market in comparison to the other two markets. Eyssell et al. (2013) notes that leading role of stock market over CDS market is in line with EMH. In the light of this literature we present following null and alternative hypotheses.

HO: KSE does not Granger cause SCDS market ${ }^{3}$.

H1: KSE Granger cause SCDS market.

Second strand of literature found the dominant role of the CDS market in incorporation of information. For instance, Chan et al. (2009) utilized data from seven Asian countries (i.e. China, Japan, Korea, Indonesia, Malaysia, Philippines and Thailand) to study the linkage between SCDS spreads and stock market returns. A negative relationship between these two markets was confirmed for all countries other than China. However, the negative relationship was observed after improvement in performance of the Chinese stock market since 2005. SCDS market dominance in the price discovery was also affirmed for most of the countries. This dominance is attributed towards ease of access in global CDS markets. Another study supporting

\footnotetext{
${ }^{2}$ Forte and Pena (2009)

${ }^{3}$ Rejection of the null hypothesis implies that stock market leads SCDS market in incorporation of information.
} 
CDS market dominance is conducted by Eyssell et al. (2013). They studied the determinants of SCDS, and its relationship with stock market in China. They found stock index as an appropriate gauge for measuring SCDS. By employing Vector Auto Regressive (VAR) model, they concluded the primary role of the SCDS market in price discovery. This role is attributed towards, high liquidity in the SCDS market due to different players (e.g. hedgers and speculators), and information access to large investors present in the SCDS market. While the stock markets secondary role in price discovery, is an indication of its less proficiency. Above-mentioned literature guide us to propose following null and alternative hypotheses.

H0: SCDS market does not Granger cause KSE ${ }^{4}$. H1: SCDS market Granger cause KSE.

\subsection{Outliers and detection of outliers}

In the words of Box et al. (2013), Time series observations may sometimes be affected by unusual events, disturbances, or errors that creates spurious effects in the series. This results in extraordinary patterns in the observations that are not in accord with most observations in the time series. Such unusual observations may be referred to as outliers. In simple words, outliers are abnormal values present in data and these values are usually different from the rest of the observations.

Outliers can prevail in data due to uncommon events like political or economic shocks, or they can also occur due to recording or measurement errors. However, existence of outliers within time series data can have a significant effect on forecasting and parameter estimation (Box et al., 2013).Outliers can cause miss-specified models, biasness in estimation of parameters, and poor forecasting. Hence detection of outliers is very crucial in time series data (Tsay et al., 2000). Several Researchers have recommended detection of outliers as an important aspect of data processing (Chen et al., 2010).

Keeping in view the importance of outlier detection, Adil (2012) developed Split Sample Skewness Based Boxplot (SSSBB) technique to deal with outliers in skewed data and noted following distinctions of this technique over the existing outlier detection techniques. First, it is superior to the famous box plot technique developed by Tukey (1977). Second, SSSBB moves the critical values interval towards the side where data is more skewed instead of moving it towards the compressed sides. Hence, SSSBB technique shifts the critical values interval towards the actual position of the data. Finally, Adil (2012) states fences of SSSBB are always close to the true 95\% fence as compared to Tukey and Kimber technique fences.

\footnotetext{
${ }^{4}$ Rejection of null implies that SCDS market leads stock market
} 


\section{Methodology}

\subsection{Data and Sample Size}

We use daily data for the SCDS market of Pakistan and the KSE 100 Index. 5-year SCDS contracts are more frequently traded in the SCDS market, which make these contracts more liquid as compare to other SCDS contracts. Previous researchers have also used these SCDS contracts (e.g. Chan et al. (2009), and Eyssell et al. (2013). Our analysis is also based upon the dollar quoted 5-year SCDS contracts, which are obtained from the Bloomberg database. Moreover, data for KSE-100 index has been taken from Karachi Stock Exchange official website. Our sample consists of daily data from October 12, 2004, to December 31, $2012^{5}$.

\subsubsection{Sub samples}

To analyze the effect of financial crisis 2008 on the relationship between the stock market and SCDS market, we divide our data into three sub-samples/periods. The first period consists of data from October 12, 2004, to August 8, 2007, and it represents pre-crisis period. The second period contains data from August 9, 2007, to May 29, 2009, and represents crisis period. There are two main reasons for considering this period as crisis period. Firstly, the global financial crisis of 2008 affected the financial markets globally. Moody ${ }^{6}$ has highlighted the emergence of three major problems due to financial crisis 2007-08: (1) It has slowed global economic growth by grasping both emerging and developed countries; (2) There was an increase in downgrade rating of sovereign entities; (3) Two countries Seychelles and Ecuador defaulted on their international payments in 2008 as well. Kim et al. (2010) have noted that global financial crisis has also affected the Asian borrowers. Secondly, there was a domestic crisis in Pakistan. Pakistan was facing political instability, poor law and order situation, and lawyers movement. Due to instability in the country, there was an outflow of $\$$ 177.7 million in Foreign Portfolio Investment (FPI) during 2008. After elimination of the price floor from KSE, the outflow was increased to $\$ 418.4$ million during the first quarter of 2009. Due to these issues the Pakistani stock market observed a negative growth of $50.7 \%$ for fiscal year $2008-09^{7}$.

In line with Kim et al. (2010), we consider August 9, 2007, as the starting date of financial crisis. As separation in effect of global and domestic crisis from both markets, is an uphill task, so we consider crisis period from starting date of global financial crisis till May 29, 2009, for both markets. Our third period comprises of data from June 1, 2009, to December 31, 2012, and it represents the post-crisis period.

\footnotetext{
${ }^{5}$ Missing data points are generated through linear interpolation. Moreover, the time difference between both markets is adjusted through taking lag of SCDS market.

${ }^{6}$ See Moodys Global credit policy report (March,2009).

${ }^{7}$ Pakistan Economic Survey 2008-09
} 


\subsection{Model}

We apply the Granger causality model to study the causal relationship between Change in Sovereign Credit Default Swap Spreads (CSCDS) and Returns of KSE (RKSE). This model is developed by Granger (1969) and it has become standard model for studying the causal relationship between variables of interest. Granger (1969) defined causality: a variable is said to Granger-cause , if can be predicted with greater accuracy by using past values of the variable rather than not using such past values, all other terms remaining unchanged. Application of this model consists of the following steps. At first, we check for Co-Integration between both markets. If markets are Co-integrated, it means they have the long run relationship. However, markets are not Co-integrated in our case. Thus, we test for the stationarity of both markets data at the first difference ${ }^{8}$. As our data is stationary so we move to the following Granger causality model to test the short run relationship between both markets:

$$
\begin{aligned}
& R K S E_{t}=a_{1}+\sum_{i=1}^{n} \beta_{i} R K S E_{t-i}+\sum_{j=1}^{m} \gamma_{j} \operatorname{CSCDS}_{t-j}+\mu_{1 t} \\
& \operatorname{CSCDS}_{t}=\alpha_{2}+\sum_{i=1}^{n} \theta_{i} R K S E_{t-i}+\sum_{j=1}^{m} \lambda_{j} \operatorname{CSCD} S_{t-j}+\mu_{2 t}
\end{aligned}
$$

$R K S E_{t}:$ KSE 100 Index Returns in the time period $\mathrm{t}$

$\operatorname{CSCDS} S_{t}$ : Change in Sovereign Credit Default Swap Spreads in time period t. While $\mu_{1 t}$ and $\mu_{2 t}$ are uncorrelated white-noise error terms.

Asteriou and Hall (2007) note four outcomes of Granger causality model, which can be written as under.

Outcome 1: The lagged CSCDS terms in (1) may be statistically different from zero as a group, and the lagged RKSE terms in (2) may not be statistically different from zero. Then we can conclude that $C S C D S_{t}$ Granger causes $R K S E_{t}$ or SCDS market leads KSE.

Outcome 2: The lagged RKSE terms in (2) may be statistically different from zero as a group, and the lagged CSCDS terms in (1) may not be statistically different from zero. So we can conclude that $R K S E_{t}$ Granger causes $C S C D S_{t}$ or KSE leads SCDS. Outcome 3: Both sets of the RKSE and CSCDS terms are statistically different from zero in (1) and (2), so we have bi-directional causality.

Outcome 4: Both sets of the RKSE and CSCDS terms are not statistically different from zero in (1) and (2), so we can say that both $R K S E_{t}$ and $C S C D S_{t}$ are independent of each other.

\footnotetext{
${ }^{8}$ Results of Augmented Dickey-Fuller (ADF) and Phillips-Perron (PP) tests show that both markets data is stationary at first difference.
} 
To check the effect of outliers on the causal relationship between SCDS market and KSE, we first test the Granger causality between both markets without handling outliers. Afterwards, we re-run the model after handling outliers through SSSBBWinsorization, which is explained in next section.

\subsection{Handling of outliers}

Trimming and Winsorizing are the two widely used techniques in literature to deal with outliers. Trimming or truncation is discarding of certain extreme values out of the data. Basically it removes tails of data and focuses on the middle part of a data distribution (Wilcox, 2005). For example, 95\% trimming means that the data is trimmed at 95th and 5 th percentiles. While Winsorization replaces the smallest and largest values by their adjoining values. For example, in 95\% Winsorization, 95th percentiles value replaces values more than the 95th percentile. Similarly, the values that are less than the 5th percentile are replaced by the value of the 5th percentile. The difference between these two techniques is that trimming exclude extreme values, but Winsorization neutralize these values with less extreme values. Trimming assumes that tails have no or insignificant information, which is not true, therefore, trimming data is not an appropriate measure in every case Wilcox (1998). Due to this deficiency, we avoid the use of trimming and propose a modified technique for Winsorization of the data named as SSSBB-Winsorization.

Let $X_{1}, X_{2}, X_{3} \ldots X n$ be the series of return from both markets and $X_{1} \leq X_{2} \ldots \leq X_{n}$ be the ascending order of returns. Our Winsorizing strategy for this data is explained in following formula.

$$
w_{i}=\left\{\begin{array}{crr}
X_{L B} & \text { if } & X_{i} \leq X_{L B} \\
X_{i} & \text { if } & X_{L B} \leq X_{i} \leq X_{U B} \\
X_{U B} & \text { if } & X_{i} \geq X_{U B}
\end{array}\right.
$$

$W_{i}$, represents the Winsorization process. LB and UB are the Lower Bound and Upper Bound respectively, calculated through SSSBB. When a value of $X$ lies below LB or above UB then it is replaced by the value of LB or UB accordingly.

To calculate LB and UB, split the data sample into two parts, on the basis of median, and treat the upper and lower sides as a separate data. Then find different percentiles (i.e. 87.5th, 62.5th, 37.5th, and 12.5th percentile) for both sides. In the next step, determine LB and UB values through 4 and 5.

For Upper Bound (UB)

$$
Q_{3 R}+1.5 * I Q_{R R}
$$

Where $Q_{3 R}=87.5$ th Percentile, $Q_{1 R}=62.5$ th Percentile, and $I Q_{R R}=Q_{3 R}-Q_{1 R}$

For Lower Bound (LB)

$$
Q_{1 L}-1.5 * I Q_{R L}
$$


Where $Q_{1 L}=12.5$ th Percentile, $Q_{3 L}=37.5$ th Percentile, and $I Q_{R L}=Q_{3 L}-Q_{1 L}$

We prefer SSSBB-Winsorization over traditional Winsorization methods because it affect fewer observations. For example, for KSE data, during the crisis period, there is no value below the lower bound, and only 2 values are outside the upper bound. Thus, we replace only two values through SSSBB-Winsorization. On the other hand, usage of conventional method, even for $99 \%$ level, would have Winsorize 10 values. Moreover, our strategy also cater for the skewness of data which is not the case with traditional Winsorizing methods. SSSBB- Winsorization is applicable to financial markets (e.g. stock, CDS and other markets) as data from these markets is generally non-normally distributed.

Table 1: Descriptive Statistics

The table depicts the characteristics of data for the full sample period i.e. from October 12, 2004, to December 31, 2012. RKSE represents the returns of KSE 100 index, WRKSE represents RKSE 100 index after Winsorization of outliers, CSCDS represents Change in Sovereign Credit Default Swap Spreads of Pakistan, and WCSCDS represent CSCDS market after Winsorization of outliers.

\begin{tabular}{lllll}
\hline & RKSE & WRKSE & CSCDS & WCSCDS \\
\hline Mean & 0.00053 & 0.000425 & 0.000373 & 0.000107 \\
Maximum & 0.082547 & 0.034034 & 0.431211 & 0.096961 \\
Minimum & -0.060418 & -0.044785 & -0.358133 & -0.071358 \\
Std. Dev. & 0.013802 & 0.013357 & 0.042312 & 0.026781 \\
Skewness & -0.375637 & -0.633774 & 1.918074 & 0.66246 \\
Kurtosis & 5.867196 & 4.970887 & 35.1872 & 6.522878 \\
Jarque-Bera & $784.8136^{\star * *} 490.5360^{* * *} 93865.40^{\star * *} 1265.503^{\star * *}$ \\
Observations & 2145 & 2145 & 2145 & 2145 \\
\hline
\end{tabular}

*** shows the $1 \%$ level of significance

For SCDS market, we Winsorize $3.9 \%, 2.2 \%, 4.6 \%$, and $4.5 \%$ values for the full period, pre-crisis, crisis, and post crisis periods respectively. For KSE market, we Winsorize $1.9 \%, 0.6 \%, 0.42 \%$, and $2.6 \%$ data for full period, pre-crisis, crisis, and post-crisis periods respectively. 


\section{Empirical Results and Analysis}

\subsection{Descriptive Statistics}

Table 1 shows the distributional characteristics of the SCDS and KSE10. Summary statistics unfold that both markets do not follow normal distribution as evident from reported values of Jarque-Bera, kurtosis, and Skewness. Observation of summary statistics in the presence of outliers, highlights negatively skewed distribution of RKSE and positively skewed distribution of CSCDS. The standard deviation of CSCDS is high as compared to RKSE, which reveals high volatility of the SCDS market. The distributional characteristics of both markets show a different picture when outliers are handled via SSSBB-Winsorization. For instance, there is observation of the declining trend in standard deviation (from $4.2 \%$ to $2.6 \%$ ) and Skewness (from 1.91 to 0.6 ) of the SCDS market. Similar declining trend is also observed in KSE. The value of kurtosis and Jarque-Bera also change significantly for both markets. Thus, the presence of outliers change the distributional characteristics of data.

\subsection{Relationship between stock and SCDS market}

To analyze relationship between both markets, pairwise correlation is calculated. Results depict that both markets move in opposite direction and are getting more connected over the time. Correlation coefficient is significant for all periods except the crisis period. Moreover, to check the effect of outliers on the correlation between two markets, we calculate the correlation coefficient before and after treating outliers.

Panel (A) of Table 2, shows the correlation between CSCDS and RKSE before treatment of outliers (i.e. through SSSBB-Winsorization). Negative correlation is evident between CSCDS and RKSE for all periods. However, changes in significance level of correlation are observed. For instance, correlation is insignificant for the crisis period.

\section{Table 2: Pairwise Correlation}

This table summarizes the pairwise correlation between returns of KSE 100 index

(RKSE) and changes in Sovereign Credit Default Swap Spreads (CSCDS) for Pakistan. Full sample period covers data from October 12, 2004, to December 31, 2012. Pre-crisis period includes time period of October 12, 2004, to August 8, 2007.

Crisis period covers time period from August 9, 2007, to May 29, 2009. The post-crisis period comprises of data from June 1, 2009, to December 31, 2012.

Panel $(A)$ represents data with occurrence of outliers. While Panel $(B)$ represents data after SSSBB-Winsorization of outliers and $\rho$ is correlation coefficient 


\begin{tabular}{lll}
\hline & Panel A & Panel B \\
\hline Time Period & $\rho$ & $\rho$ \\
Full Sample & $-0.061^{* *}$ & $-0.096^{\star * *}$ \\
Pre-crisis & $-0.079^{*}$ & $-0.094^{*}$ \\
Crisis & -0.042 & -0.057 \\
Post-crisis & $-0.067^{* *}$ & $-0.13^{\star * *}$ \\
\hline
\end{tabular}

${ }^{* * *}$, ${ }^{* *}$ and ${ }^{*}$ shows significance at $1 \%, 5 \%$ and $10 \%$ level

Panel (B) of Table 2, presents the results after detection and treatment of outliers. The correlation is negative and significant for the full time period. However, we observe an increase in magnitude of the correlation coefficient $(\rho)$ from $6 \%$ to $9.6 \%$, which shows an understatement in magnitude of due to outliers.

Analysis of pre-crisis, crisis and post-crisis period discloses some more findings related to the effect of outliers. For instance, the magnitude and significance level of is overstated for pre-crisis period due to outliers. On the contrary, is understated for crisis and post-crisis period. Furthermore, the significance level of is also understated for the post - crisis period. One important finding about is that it shows an increase (from $6.7 \%$ to $13 \%$ ) for post-crisis period. It highlights that SCDS and KSE are getting more correlated after the financial crisis of 2008. Results depicts that the presence of outliers bring forth misleading information about for SCDS and KSE in following two aspects. First, due to the presence of outliers, magnitude of the $\rho$ is either overstated or understated. Second, significance level of is also misleading.

\subsection{Granger causality}

This study tests two null hypotheses: 1) SCDS does not Granger cause KSE; and 2) KSE does not Granger cause SCDS. At first, we conduct the Granger causality test before detecting and treating outliers. Then, we test the Granger causality between both markets after treatment of outliers (i.e. SSSBB-based Winsorization). Table 3 presents the results of Granger causality without Winsorization of outliers in data. The null hypothesis of SCDS does not Granger cause KSE is not rejected at any significance level for full sample or all sub-samples except for post-crisis period. It points out the existence of no causal relationship from the SCDS market towards KSE prior to financial crisis of 2008. Similarly, null hypothesis of KSE does not Granger cause SCDS is not rejected for full sample, pre-crisis, and crisis period. It indicates non-existence of causal relationship for KSE towards SCDS market. However, in the post-crisis period, our null hypothesis of KSE does not Granger cause SCDS is rejected at $5 \%$ level of significance. This rejection points out that KSE Ganger causes the SCDS. 
Table 3: Granger causality Wald tests (With Outliers)

The results of Granger causality test based on the equations (1\&2) are summarized in this table. We test two null hypotheses: 1) $H_{0}=\sum_{j=1}^{m} \gamma_{j}=0$ or SCDS does not Granger cause KSE against $H_{1}: \Sigma_{j=1}^{m} \gamma_{j} \neq 0$ or SCDS Granger causes KSE; and 2) $H_{0}=\sum_{i=1}^{n} \theta_{i}=0$ or KSE does not Granger cause SCDS against $H_{1}=\sum_{i=1}^{n} \theta_{i} \neq 0$ or KSE

Granger cause SCDS. The full sample period covers time period from October 12, 2004, to December 31, 2012. Pre-crisis period includes time period of October 12, 2004, to August 8, 2007. Crisis period covers time period from August 9, 2007, to May 29, 2009. Post-crisis period comprises of data from June 1, 2009, to December 31, 2012.

Obs represents the number of observations, Df represents the number of lags selected on the basis of AIC (Akaike Information Criterion), $\chi^{2}$ represents values of Chi-square statistics, SCDS is Change in Sovereign Credit Default Swap Spreads, and KSE is returns of KSE 100 index.

\begin{tabular}{|c|c|c|c|c|}
\hline & Null Hypothesis & $\mathrm{Df}$ & Obs & $\chi^{2}$ \\
\hline \multirow[t]{2}{*}{ Full sample } & $\begin{array}{l}\text { SCDS does not Granger cause } \\
\text { KSE }\end{array}$ & 1 & 2144 & 1.3323 \\
\hline & $\begin{array}{l}\text { KSE does not Granger cause } \\
\text { SCDS }\end{array}$ & 1 & & 0.88699 \\
\hline \multirow[t]{2}{*}{$\begin{array}{l}\text { Pre-crisis } \\
\text { period }\end{array}$} & $\begin{array}{l}\text { SCDS does not Granger cause } \\
\text { KSE }\end{array}$ & 2 & 735 & .1609 \\
\hline & $\begin{array}{l}\text { KSE does not Granger cause } \\
\text { SCDS }\end{array}$ & 2 & & 0.6286 \\
\hline \multirow[t]{2}{*}{ Crisis Period } & $\begin{array}{l}\text { SCDS does not Granger cause } \\
\text { KSE }\end{array}$ & 1 & 471 & 0.21757 \\
\hline & $\begin{array}{l}\text { KSE does not Granger cause } \\
\text { SCDS }\end{array}$ & 1 & & 0.28855 \\
\hline \multirow[t]{2}{*}{ Post Crisis } & $\begin{array}{l}\text { SCDS does not Granger cause } \\
\text { KSE }\end{array}$ & 1 & 935 & $3.6383^{*}$ \\
\hline & $\begin{array}{l}\text { KSE does not Granger cause } \\
\text { SCDS }\end{array}$ & 1 & & 0.31592 \\
\hline
\end{tabular}

Table 4 explains the results after SSSBB-Winsorization of outliers. Our first null hypothesis, SCDS does not Granger cause KSE, is not rejected at any significance 
level for full time period and all sub-periods except post-crisis period. Our second null hypothesis, KSE does not Ganger cause SCDS is rejected at $5 \%$ level of significance for the full sample. It infers that KSE Granger causes the SCDS. This leading role of KSE over the SCDS market is supported by efficient market hypothesis. An important point to consider here is that the same null hypothesis is not rejected before treating outliers. This finding supports the argument of Wilcox (2005) that outliers can decrease hypothesis testing power.

In the case of sub-periods, our second null hypothesis, KSE does not Granger causes SCDS is not rejected for pre-crisis and crisis periods. However, for post-crisis period, we reject the null hypothesis of KSE does not Granger cause SCDS at $5 \%$ level of significance. The rapid growth of KSE during this period may well explain the role of KSE in Granger causing SCDS market. For this period, KSE 100 index shows $134 \%$ growth. One important component of this growth is an increase (i.e. 221\%) in holdings of foreign investors in KSE, during this period. Thus, we argue that stock market is an important player in price discovery during growth periods. On the other hand, in line with previous literature (e.g. Eyssell et al. (2013)), we find strong feed-back affect from SCDS for this period as our null of SCDS Granger cause KSE is rejected at $1 \%$ level of significance. The findings suggest that after financial crisis of 2008, both markets have become important for price discovery.

Overall findings suggest that presence of outliers is depicting misleading picture of causal relationship and SSSBB-Winsorization increase precision of results as evident from increase in magnitude of statistics (see table 4).

Table 4: Granger causality Wald tests (Winsorized Outliers)

The results of Granger causality test based on the equations (1 \& 2) are summarized in this table. We test two null hypotheses: 1) $H_{0}=\sum_{j=1}^{m} \gamma_{j}=0$ or SCDS does not Granger cause KSE against $H_{1}: \Sigma_{j=1}^{m} \gamma_{j} \neq 0$ or SCDS Granger causes KSE; and 2) $H_{0}=\sum_{i=1}^{n} \theta_{i}=0$ or KSE does not Granger cause SCDS against $H_{1}=\sum_{i=1}^{n} \theta_{i} \neq 0$ or KSE

Granger cause SCDS. The full sample period covers time period from October 12, 2004, to December 31, 2012. Pre-crisis period includes time period of October 12, 2004, to August 8, 2007. Crisis period covers time period from August 9, 2007, to May 29 , 2009. Post-crisis period comprises of data from June 1, 2009, to December 31, 2012.

Obs represents the number of observations, Df represents the number of lags selected on the basis of AIC (Akaike Information Criterion), $\chi^{2}$ represents values of Chi-square statistics, SCDS is Change in Sovereign Credit Default Swap Spreads, and KSE is returns of KSE 100 index. 


\begin{tabular}{|c|c|c|c|c|}
\hline & Null Hypothesis & $\mathrm{Df}$ & Obs & $\chi^{2}$ \\
\hline \multirow[t]{2}{*}{ Full sample } & $\begin{array}{l}\text { SCDS does not Granger cause } \\
\text { KSE }\end{array}$ & 1 & 2144 & 42.5351 \\
\hline & $\begin{array}{l}\text { KSE does not Granger cause } \\
\text { SCDS }\end{array}$ & 1 & & $5.3339^{* *}$ \\
\hline \multirow[t]{2}{*}{$\begin{array}{l}\text { Pre-crisis } \\
\text { period }\end{array}$} & $\begin{array}{l}\text { SCDS does not Granger cause } \\
\text { KSE }\end{array}$ & 2 & 735 & 1201 \\
\hline & $\begin{array}{l}\text { KSE does not Granger cause } \\
\text { SCDS }\end{array}$ & 2 & & 1.508 \\
\hline \multirow[t]{2}{*}{ Crisis Period } & $\begin{array}{l}\text { SCDS does not Granger cause } \\
\text { KSE }\end{array}$ & 1 & 471 & 1.0105 \\
\hline & $\begin{array}{l}\text { KSE does not Granger cause } \\
\text { SCDS }\end{array}$ & 1 & & 0.3952 \\
\hline \multirow[t]{2}{*}{ Post Crisis } & $\begin{array}{l}\text { SCDS does not Granger cause } \\
\text { KSE }\end{array}$ & 1 & 935 & $10.814^{\star * *}$ \\
\hline & $\begin{array}{l}\text { KSE does not Granger cause } \\
\text { SCDS }\end{array}$ & 1 & & $4.0714^{* *}$ \\
\hline
\end{tabular}

\section{Conclusion}

This study focuses on the correlation and causal relationship between the SCDS market for Pakistan and KSE-100 Index. We find statistically significant negative correlation between these markets. Analysis of pre, post, and crisis periods depict that the correlation between KSE and SCDS has improved significantly after the financial crisis of 2008. This improvement is an indication of the more connectivity of KSE with SCDS. Our findings on causal relationship depicts that KSE is Granger causing the SCDS for full sample. For pre-crisis and crisis periods, both the markets have failed to cause each other. However, during the post-crisis period, feed-back effect from both markets is observed. The findings suggest that both markets are efficient in incorporation of information related to the sovereign credit risk of Pakistan. Furthermore, the price discovery function between both markets varies with market dynamics.

This study use SSSBB-Winsorization strategy for outliers handling and find that they significantly affect the correlation and causal relationship. Thus future studies in this area could use this strategy for better results. Additionally, efficiency of this technique needs to be further tested by applying to a larger sample of countries. Finally, this strategy can be applied to other financial market studies as these markets generally contain skewed data. 


\section{References}

Adil, I. (2012). Robust Outlier Detection Techniques for Skewed Distributions and Applications to Real Data. PhD thesis, International Islamic University, Islamabad.

Akbar, M. and Nguyen, T. T. (2016). The explanatory power of higher moment capital asset pricing model in the Karachi stock exchange. Research in International Business and Finance, 36:241253.

Asteriou, D. and Hall, S. G. (2007). Applied econometrics: a modern approach, revised edition. Hampshire: Palgrave Macmillan.

Box, G., Jenkins, G., Reinsel, G., and Ljung, G. (2013). Time series analysis: forecasting and control. Wiley, fifth edition.

Bystrom, H. (2005). Credit default swaps and equity prices: The iTraxx CDS index" market. Working Papers.

Chan, K. C., Fung, H.-G., and Zhang, G. (2009). On the relationship between Asian credit default swap and equity markets. Journal of Asia Business Studies, 4(1):3-12.

Chan-Lau, J. A. and Kim, Y. S. (2004). Equity prices, credit default swaps, and bond spreads in emerging markets. International Monetary Fund, (4-27).

Chen, Y., Miao, D., and Zhang, H. (2010). Neighborhood outlier detection. Expert Syst Appl, 37(12):8745-8749.

Coronado, M., Corzo, T., and Lazcano, L. (2012). A case for Europe: the relationship between sovereign CDS and stock indexes. Frontiers in Finance \& Economics, 9(2).

Eyssell, T., Fung, H.-G., and Zhang, G. (2013). Determinants and price discovery of china sovereign credit default swaps. China Economic Review, 24:1-15.

Forte, S. and Pena, J. I. (2009). Credit spreads: An empirical analysis on the informational content of stocks, bonds, and CDS. Journal of Banking \& Finance, 33(11):2013-2025.

Granger, C. (1969). Investigating causal relations by econometric models and cross spectral methods. Econometrica.

Huang, A., Chen, C., and Shen, C. (2014). Dynamics of sovereign credit contagion. The Journal of Derivatives.

Kim, D., Loretan, M., and Remolona, E. (2010). Contagion and risk premia in the amplification of crisis: Evidence from asian names in the global CDS market. Journal of Asian Economics, 21(3):314326.

Longstaff, F., Mithal, S., and Neis, E. (2003). The credit default swap market: is credit protection priced correctly? 
Merton, R. (1974). On the pricing of corporate debt: The risk structure of interest rates*. The Journal of Finance, 29(2).

Norden, L. and Weber, M. (2009). The Co-movement of Credit Default Swap, Bond and Stock Markets: an Empirical Analysis. European Financial Management, 15(3):529-562.

Tsay, R., Pena, D., and Pankratz, A. (2000). Outliers in multivariate time series. Biometrika.

Tukey, J. W. (1977). Exploratory data analysis.

Wilcox, R. (2005). Trimming and Winsorization. Encyclopedia of Biostatistics. 8. John Wiley Sons, Ltd. DOI: 10.1002/0470011815.b2a15165

Wilcox, R. R. (1998). The goals and strategies of robust methods. British Journal of Mathematical and Statistical Psychology, 51(1):1-39. 